\title{
Satovahinkovakuutusten hintataso ja viljelijöiden maksuhalukkuus
}

\author{
Sami Myyrä ${ }^{1)}$, Petri Liesivaara ${ }^{1)}$ ja Minna Väre ${ }^{1)}$ \\ ${ }^{1)}$ MTT taloustutkimus, Latokartanonkaari 9, 00790 Helsinki, etunimi.sukunimi@mtt.fi
}

\section{Tiivistelmä}

Satovahinkojen vakuutusjärjestelmä on uudistumassa. Muutaman vuoden sisällä siirrytään järjestelmään, jossa satovahingot korvataan valtion ja yksityisten vakuutusyhtiöiden yhdessä tarjoamilla satovahinkovakuutuksilla. EU:ssa on ehdolla tuki satovahinkovakuutusten vakuutusmaksuille. Tuettujen vakuutusten enimmäistukimäärä voisi olla $65 \%$ vakuutuksen hinnasta. Vakuutusmaksutuen turvin vakuutusyhtiöillä on selkeät kannusteet satovahinkovakuutusten kehittämiseen ja niiden tuomiseen markkinoille.

Vakuutustuotteiden kehitystyössä hinnoittelu on keskeisessä asemassa. Hinnoittelun rooli korostuu erityisesti markkinoilla, joilla ei aikaisemmin vastaavia tuotteita ole ollut. Asiakkaiden hintatietoisuus vakuutustuotteiden suhteen on olematonta, eikä vakuutusten sisältöä ja rajauksia, kuten omavastuuta ja odotettavissa olevia korvauksia, ole päätetty. Niin viljelijät kuin vakuutusyhtiötkin ovat suurten haasteiden edessä arvioidessaan vakuutusten oikeaa hintaa.

Tässä tutkimuksessa selvitettiin tarjotun hintatason vaikutusta viljelijöiden maksuhalukkuuteen satovahinkotuotteista, kun vakuutustuote on sama. Tutkimuksessa käytettiin valintakoemenetelmää. Valintakoemenetelmä perustuu oletukseen, että viljelijöiden kokema hyöty satovahinkovakuutuksista voidaan jakaa osiin vakuutuksen attribuuttien suhteen. Valintakokeeseen valitut vakuutusten attribuutit olivat: hinta, omavastuu, vakuutuksen tyyppi ja odotettavissa oleva vakuutuskorvaus. Hintatason vaikutusta tutkittiin jaetulla aineistolla. Aineistossa hintatasoina käytettiin matalia hintoja: 4,8 ja $12 € /$ ha sekä korkeita hintoja: 16, 24 ja $32 € /$ ha. Muut attribuutit vaihtelivat molemmissa hintaryhmissä samalla tavalla.

Tarjotuilla hintatasoilla oli merkitsevä vaikutus viljelijöiden satovahinkotuotteisiin esittämään maksuhalukkuuteen. Tarjottaessa korkean hintatason vakuutuksia oli maksuhalukkuus suurempi kuin matalan hintatason vakuutuksissa, vaikka tuotteet olivat molemmilla hintatasoilla identtisiä. Tulos kertoo siitä, että vakuutusmarkkinoiden kehittyminen on iteroituva prosessi, jossa markkinaosapuolien käsitys vakuutustuotteiden hinnoista muuttuu ajan myötä.

Vakuutusten oikeudenmukaisen hinnan eli hinnan, jolla kerättävät vakuutusmaksut ja maksettavat vakuutuskorvaukset ovat samansuuruiset, laskeminen edellyttää tarkkoja tilastoja satovaihtelusta. Tämän tiedon puuttuessa markkinoilla on sekä moraalikadosta että haitallisesta valikoitumisesta johtuvia haasteita. Tämän tutkimuksen mukaan näiden haasteiden lisäksi kehittyvillä markkinoilla etsitään myös satovahinkovakuutuksiin liittyvää hintatietoisuutta.

Asiasanat satovahinkovakuutus, maksuhalukkuus, valintakoemenetelmä. 


\section{Johdanto}

Satovahinkojen vakuutusjärjestelmä on uudistumassa. Muutaman vuoden sisällä siirrytään järjestelmään, jossa satovahingot korvataan valtion ja yksityisten vakuutusyhtiöiden yhdessä tarjoamilla satovahinkovakuutuksilla. EU:ssa on ehdolla tuki satovahinkovakuutusten vakuutusmaksuille. Tuettujen vakuutusten enimmäistukimäärä voisi olla $65 \%$ vakuutuksen hinnasta. Vakuutusmaksutuen turvin vakuutusyhtiöillä on selkeät kannusteet satovahinkovakuutusten kehittämiseen ja niiden tuomiseen markkinoille.

Uusien vakuutusten kehittely on haastavaa. Vakuutusyhtiöiden täytyy kerätä dataa vakuutettavasta ilmiöstä, suunnitella vakuutustuotteita ja lisäksi hinnoitella ne niin, että ne menevät kaupaksi. Vakuutusten suunnittelua vaikeuttaa se, että satovahinkovakuutukset kärsivät muiden vakuutusten tapaan moraalikadosta sekä valikoitumisongelmasta. Moraalikadolla tarkoitetaan sitä, että viljelijä voi vakuutuksen ottamisen jälkeen muuttaa viljelykäytäntöjään niin, että satovahingon todennäköisyys lisääntyy. Valikoitumisongelma taas aiheuttaa sen, että vakuutusyhtiön tiskille tulevat ensimmäisinä ne viljelijät, joilla on suurimmat satoriskit. Molempien ongelmien taustalla on epäsymmetrinen informaatio. Viljelijä tietää enemmän oman tilansa satovaihtelusta ja siihen vaikuttavista tekijöistä kuin vakuutusyhtiö (Smith ja Goodwin 1996).

Maatalouspolitiikan uudistuksen myötä EU:ssa otetaan käyttöön vakuutusmaksutuki. Tuki voi olla enimmillään 65 \% vakuutuksen hinnasta (EC 2013). Vakuutusyhtiöiden asettama hinta on siis erittäin tärkeässä asemassa. Hinnan asettamisen oikeellisuutta arvioidaan yleensä ns. "fair" eli oikeudenmukaisen hinnan avulla. Fair hinnalla vakuutuksesta maksetut vakuutusmaksut ovat pitkällä aikavälillä tarkasteltuina yhtä suuria kuin vakuutusyhtiön viljelijöille maksamat vahingonkorvaukset. Fair hinnan määrittämiseen tarvitaan laaja satovaihtelua kuvaava data, joka kuvaa erikseen jokaisen tilan omaa satovaihtelua. Tätä dataa ei kuitenkaan ole vakuutusyhtiöiden käytettävissä. Kehittyvillä vakuutusmarkkinoilla tarvitaankin mittavia tukitoimia, jotta vakuutusyhtiöt lähtisivät allekirjoittamaan vastuita, joista niillä ei ole tarkkaa kuvaa (Myyrä ja Jauhiainen 2013).

Euroopassa tärkeimmät satovahinkoihin varautumisen menetelmät ovat erilaiset viljelijöiden yhteiset rahastot sekä valtion antamat ad hoc -tyyppiset satovahinkokorvaukset. Euroopassa (EU 27) ad hoc -tyyppisiä satovahinkokorvauksia on maksettu keskimäärin 920 milj. euroa vuodessa. Valtion osuus rahastoihin ja katastrofiapuun on yleensä organisoitu erilaisten ohjelmien kautta. Vakuutusten kokonaisrahoitus muodostuu sekä viljelijöiden että valtion osuudesta ja politiikkauudistuksen myötä viljelijän osuuden on oltava vähintään $35 \%$. Tuki kohdistuu usein jälleenvakuuttamiseen, joka hoidetaan joko suoraan valtioiden toimesta tai yksityisten vakuutusyhtiöiden kautta valtion tukemana. Eräissä EUmaissa satovahinkovakuutuksia edistetään erityisellä lainsäädännöllä, joka kieltää ad hoc -tyyppiset valtion satovahinkokorvaukset. Esimerkiksi Ranskassa, Kreikassa, Espanjassa, Itävallassa, Portugalissa sekä Ruotsissa viljelijöiden ei ole mahdollista saada valtiolta minkään tyyppisiä satovahinkokorvauksia, jos kaupallisia satovahinkovakuutuksia on tarjolla. Romaniassa valtion antama satovahinkokorvaus on sidottu siihen, että viljelijä on ensin itse vakuuttanut yleisimmät satoriskit satovahinkovakuutuksilla (Bielza Diaz-Caneja et al. 2009).

Pohjois-Amerikassa satovahinkojen vakuuttamisen perinteet yksityisten vakuutusyhtiöiden kautta ovat pitkät. Satovaihtelua kuvaavaa tilakohtaista dataa on kerätty jo 1930-luvulta asti. Hyvä data antaa mahdollisuuden tilakohtaisesti oikeudenmukaisten hintojen laskemiseen ja vakuutusten tilakohtaiseen räätälöimiseen. Hyvästä datasta huolimatta kaikkia moraalikatoon ja haitalliseen valikoitumiseen liittyviä ongelmia ei ole pystytty ratkaisemaan (Smith ja Goodvin 1996). Hinnoittelun läpinäkyvyyttä on entisestään lisätty ottamalla käyttöön niin sanottuja indeksivakuutuksia. Indeksivakuutuksissa korvauskynnyksen ylittyminen määritetään viljelijän kannalta eksogeenisista muuttujista kuten säästä. Epäsymmetrisestä informaatiosta johtuvat moraalikato ja valikoitumisongelmat saadaan ratkaistua, mutta tilalle tulee basis-riski (Barnett et al. 2005). Empiirinen tutkimus on osoittanut, että indeksivakuutukset ovat tehokkaampia riskinhallintavälineitä erityisesti tilanteissa, joissa tilatason dataa on vähän saatavissa ja se on epäluotettavaa (Bokusheva et al. 2006). 
Euroopassa kaupallisten satovahinkovakuutusten yleistymistä hidastavat tilakohtaisen satodatan puute, katastrofiavun perinteet sekä epätietoisuus vakuutusten toiminnasta ja hinnoittelusta. Tässä tutkimuksessa keskityttiin tarkastelemaan vakuutusten hinnoitteluun liittyviä kysymyksiä. Aikaisemmasta tutkimusperinteestä poiketen emme voi laskea tilakohtaista satovahinkovakuutuksesta saatavaa odotettua hyötyä. Tässä tutkimuksessa käytetäänkin toista lähestymistapaa, joka perustuu viljelijöiden omiin valintoihin.

Tutkimuksessa selvitetään valintakoemenetelmällä viljelijöiden maksuhalukkuus erilaisista satovahinkovakuutuksista. Valintakoemenetelmän on aikaisemmin todettu antavan hyviä arvioita markkinoiden toiminnasta niiden vakiinnuttua (McFadden 2001). Yksi keskeisimmistä oletuksista valintakoemenetelmän käytössä on se, että viljelijöiden alkuperäiset preferenssit ovat kestäviä ja muuttumattomia, eikä valintakokeessa esitetyillä attribuuttien tasoilla ole merkitystä saataviin tuloksiin (Kragt 2012). Yleensä valintakoemenetelmää soveltavissa tutkimuksissa pyritäänkin siihen, että vakuutusvaihtoehtoja kuvaavissa attribuuteissa hinta on kuvattu mahdollisimman laajalla intervallilla. Tällä pyritään välttämään hintaintervallin aiheuttama vääristymä viljelijöiden valinnoissa. Tässä tutkimuksessa tarkastelu käännettiin toisin päin ja testattiin sitä, voiko vakuutusyhtiö käyttää hinnoittelustrategiaa hyväkseen ja ohjata viljelijöiden valintoja. Aikaisempi valintakoemenetelmään perustunut kirjallisuus antaa viitteitä siitä, että tämä olisi mahdollista (Kragt 2012; Luisetti et al. 2011; Morkbak et al. 2010). Tarkastelussa tuotettiin arvio viljelijöiden maksuhalukkuudesta erilaisista satovahinkovakuutusten attribuuteista sekä arvio siitä, miten vakuutusyhtiön hinnoittelustrategia vaikuttaa maksuhalukkuuteen niistä.

\section{Aineisto ja menetelmät}

Viljelijöille suunnattu valintakoekysely toteutettiin vuonna 2012. Kyselyä esitestattiin viljelijöillä, tutkijoilla sekä maataloushallinnon edustajilla. Saadun palautteen perusteella kyselyä myös muutettiin olennaisesti. Kyselylomakkeita lähetettiin kaikkiaan 5000 viljelijälle. Lomakkeita palautettiin 1170. Katoanalyysin perusteella vastaajien joukon voidaan katsoa edustavan kaikkia suomalaisia viljelijöitä.

Kyselylomakkeella viljelijöille esitettiin kuusi valintakorttia, joista jokaisella oli kaksi vakuutustuotetta ja kolmantena vaihtoehtona "En ostaisi kumpaakaan vakuutusta". Kyselylomakkeet jaettiin kolmeen yhtä suureen hintakategoriaan. Kolmasosa viljelijöistä sai lomakkeen, jossa hinnat olivat matalan hintakategorian mukaiset 4, 8, tai $12 € /$ ha. Seuraava kolmannes sai lomakkeet, jossa hinnat olivat korkean hintakategorian mukaiset 16, 24 ja $32 €$ / ha. Kolmannessa lomakeryhmässä käytettiin kaikkia hintavaihtoehtoja. Hintakategorioissa vakuutusten muut ominaisuudet olivat identtiset ja vaihtelivat satunnaisesti.

Kuva 1. Esimerkki valintakortista.

\begin{tabular}{|c|c|c|c|}
\hline VAKUUTUSKORTTI 1 & Vakuutus 1 & Vakuutus 2 & $\begin{array}{c}\text { En ostaisi } \\
\text { kumpaakaan } \\
\text { vakuutusta }\end{array}$ \\
\hline Vakuutuksen hinta $€ /$ ha & 12 & 24 & \\
\hline Omavastuu & $30 \%$ & $10 \%$ & \\
\hline Vakuutuksen tyyppi & $\begin{array}{c}\text { Satoindeksivakuutus } \\
\text { ei edellytä } \\
\text { vahinkotarkastusta tilalla }\end{array}$ & $\begin{array}{c}\text { Tilan satovakuutus } \\
\text { edellyttää } \\
\text { vahinkotarkastuksen tilalla }\end{array}$ & \\
\hline Vakuutuskorvaus $€ /$ ha & 100 & 300 & \\
\hline VALINTANI & $\square$ & $\square$ & $\square$ \\
\hline
\end{tabular}


Tutkimusmenetelmänä käytettiin viime vuosikymmeninä nopeasti kehittyneitä ja yleistyneitä ekonometrisia menetelmiä maksuhalukkuuden selvittämiseen (McFadden 2001). Valintakoemenetelmä perustuu oletukseen siitä, että hyödykkeen antama kokonaishyöty voidaan pilkkoa hyödykkeen ominaisuuksien (attribuuttien) tasolle. Siinä toisaalta oletetaan, että kuluttaja pystyy erottamaan attribuutit toisistaan ja että vastaaja pystyy laittamaan attribuuttien antamat hyödyt omalta kannaltaan tärkeysjärjestykseen. Menetelmässä vastaaja valitsee esitetyistä hyödykekoreista sen, joka tuottaa hänelle suurimman hyödyn. Valintakoemenetelmässä hyödykkeen kokonaishyöty U voidaan siis jakaa tuotteen attribuutteihin $\mathrm{Z}$ ja sosioekonomisiin taustamuuttujiin $\mathrm{S}$ :

$U_{i n}=V_{i n}\left(Z_{i}, S_{n}\right)+\varepsilon_{i n}$

Missä,

$\mathrm{U}_{\text {in }}=$ vaihtoehdon $\mathrm{i}$ antama hyöty henkilölle $\mathrm{n}$

$\mathrm{V}_{\text {in }}=$ selitettävissä oleva osa hyödystä

$\mathrm{Z}_{\mathrm{i}}=$ attribuutit

$\mathrm{S}_{\mathrm{n}}=$ sosioekonomiset taustamuuttujat

$\varepsilon_{\text {in }}=$ satunnaisvaihtelu

Hinnan lisäksi muina vakuutustuotteiden attribuutteina käytettiin vakuutuksen omavastuuta, vakuutustyyppiä ja odotettavissa olevia korvauksia. Kaikkien attribuuttien tasot ja merkitys vastaajalle selvitettiin kyselylomakkeella huolellisesti ennen valintakortteja.

Mallinnuksessa luovuttiin virhetermien $\varepsilon_{\text {in }}$ yhtäsuuruusoletuksesta käyttämällä error component logit mallia (ECM). Käytännössä tämä tarkoittaa sitä, että mallinnuksessa otettiin huomioon viljelijöiden erilaiset mieltymysten ja riskiasenteet (Train 2003):

$$
p_{n, i}=\int\left(\frac{e^{\beta V_{n, i}}}{\sum_{j=1}^{J} e^{\beta V_{n, j}}}\right) f(\beta) d \beta,
$$

missä $f(\beta)$ on tiheysfunktio, jonka kuvaamasta jakaumasta saadaan painot mixed logit -mallin ennustamille todennäköisyyksille. Mixed logit -malli antaa siis painotetun keskiarvon logit -mallin tuloksille painotettuna eri $\beta: n$ arvoilla. Mixed logit -mallissa estimoidut parametriestimaatit voivat vaihdella vastaajittain kuvastaen erilaisia mieltymyksiä ja riskiasenteita.

Hinta-attribuutin mukanaolo mallissa mahdollistaa ns. marginaalisten maksuhalukkuuksien laskemisen. Tiettyä vaihtoehdon attribuuttia koskeva marginaalinen maksuhalukkuus kertoo sen, kuinka paljon vastaaja olisi valmis maksamaan yhden yksikön suuruisesta parannuksesta kyseiseen attribuuttiin. Marginaaliset maksuhalukkuudet attribuuteille (IP) on laskettu seuraavasti:

$$
I P_{k}=-\left(\frac{\beta_{k}}{\beta_{p}}\right)
$$

missä $\beta_{\mathrm{k}}$ on $k$ attribuutin parametriestimaatti, ja $\beta_{\mathrm{p}}$ on hinta attribuutin parametriestimaatti. 


\section{Tulokset ja tulosten tarkastelu}

Tulokset osoittavat, että satovahinkovakuutuksille on kysyntää. Kysyntä reagoi sekä vakuutuksen omavastuuseen että odotettavissa oleviin vakuutuskorvauksiin. Myös vakuutustyypillä on vaikutusta viljelijöiden valintoihin.

Omavastuun nousu kymmenellä prosenttiyksiköllä esimerkiksi 20 prosentista 30 prosenttiin alentaa viljelijöiden maksuhalukkuutta satovahinkovakuutuksista keskiarvotasolla 3,0 - 5,5€ / ha (taulukko 1). Tulos on etumerkiltään looginen, sillä viljelijän omalle vastuulle jäävän satovaihtelun osuuden kasvu luonnollisesti alentaa halukkuutta vakuutuksen ostamiseen. Kyselyssä viljelijälle luotu mielikuva vakuutusten hinnasta vaikuttaa marginaaliseen maksuhalukkuuteen omavastuusta. Koko aineistosta estimoiduissa tuloksissa marginaalinen maksuhalukkuus oli $3,4 € / \mathrm{ha}$.

Myös vakuutuskorvaukseen liittyvä marginaalinen maksuhalukkuus osoittautui herkäksi vakuutusten hinnoittelulle. Matalien hintojen kategoriassa vakuutuskorvauksen nousu 100 €/ha lisäsi vakuutuksiin kohdistuvaa maksuhalukkuutta 2,4 €/ha. Korkeiden hintojen kategoriassa vastaava maksuhalukkuuden lisääntyminen oli yli kaksinkertainen 6,7 €/ha. Edes maksuhalukkuuden luottamusvälit eivät mene päällekkäin. Koko aineistosta estimoitu $100 €$ vakuutuskorvaukseen kohdistuva maksuhalukkuus oli 4,1 €/ha. Tämä kuvastaakin melko hyvin aikaisemmissa tutkimuksissa saatua käsitystä satovahinkojen esiintymistiheydestä keskimäärin kerran 20-25 vuodessa (Myyrä ja Pietola 2012).

Esitetyillä hintakategorioilla oli myös vaikutusta viljelijöiden marginaaliseen maksuhalukkuuteen erilaisista vakuutustyypeistä. Matalien hintojen kategoriassa tilakohtainen vakuutus ja indeksivakuutus koettiin lähes samanarvoisiksi, tilakohtaisiin vakuutuksiin liitetyn marginaalisen maksuhalukkuuden ollessa hieman negatiivinen. Korkeiden hintojen kategoriassa tilakohtaiseen vakuutukseen liittyi huomattava negatiivinen marginaalinen maksuhalukkuus. Vakuutusten suunnittelun kannalta tämä tarkoittaa sitä, että viljelijät eivät ole valmiita maksamaan vakuutusten tilakohtaisesta räätälöinnistä. Pikemminkin arvoa annetaan indeksivakuutuksiin liittyvälle tilojen väliselle tasapuolisuudelle sekä vakuutusten helppoudelle. Tämä siitäkin huolimatta, että indeksivakuutuksiin liittyy aina mahdollisuus , että ne eivät korvaa todellisia vahinkoja.

Taulukko 1. Marginaaliset maksuhalukkuudet $€ /$ ha eri hinta kategorioissa.

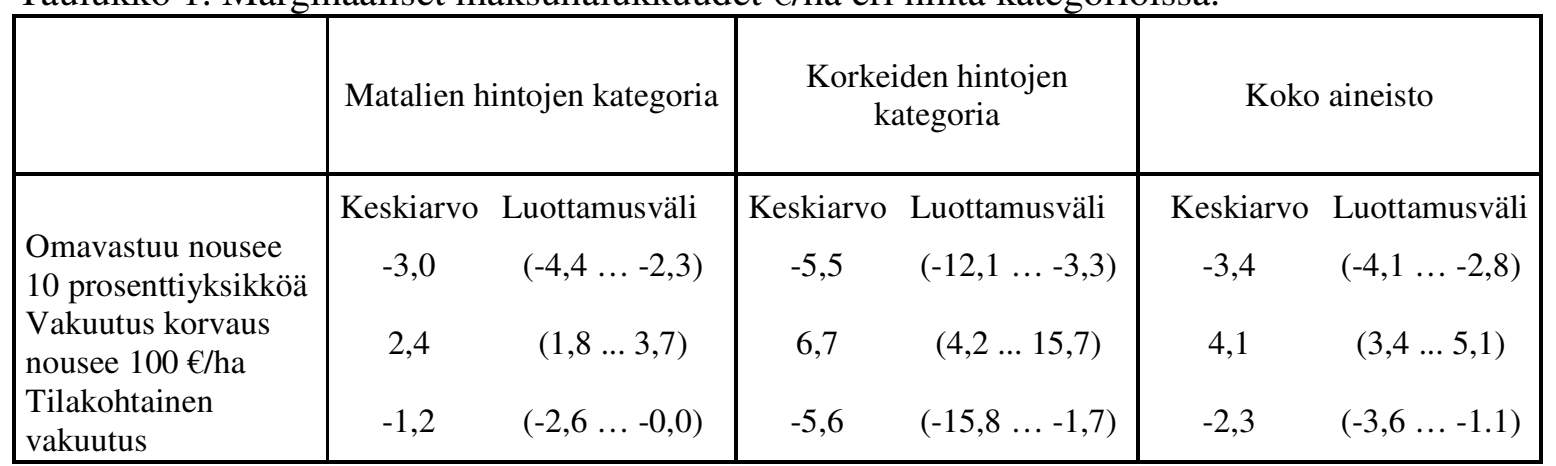

(luottamusväli kuva marginaalisen maksuhalukkuuden jakauman 2,5\% ja 97,5 \% persentiilit.) 


\section{Johtopäätökset}

Tulos kuvastaa sitä, ettei viljelijöillä ole kovin tarkkaa kuvaa vakuutusten hinnoitteluperusteista. Omavastuuseen sekä vakuutuskorvauksen tasoon liittyvät marginaalisen maksuhalukkuuden alkuperäiset preferenssit eivät ole kovinkaan vahvoja ja kyselyssä esitetyillä hinnoilla voitiin niihin vaikuttaa. Tutkimusmenetelmässä tämä vaikutus voidaan kuitenkin ottaa huomioon harhattomien tulosten saavuttamiseksi.

Kyselyssä viljelijät jakautuivat satunnaisesti hintakategoriaryhmiin, joten todellinen satovaihtelu on molemmissa ryhmissä olevilla viljelijöillä sama. Maksuhalukkuuden erot matalan ja korkean hintaryhmän välillä johtuvat pelkästään esitettyjen hintavaihtoehtojen erosta.

\section{Kirjallisuus}

Barnett, B., Black, R., Hu, Y. \& Skees, J. 2005. Is Area Yield Insurance Competitive with Farm Yield Insurance? Journal of Agricultural and Resource Economics 30: 285-301.

Bielza Diaz-Caneja, M., Conte, C. G., Gallego Pinilla, F. J., Stroblmair, J., Catenaro, R. \& Dittmann, C. 2009. Risk management and Agricultural insurance schemes in Europe. JRC Reference Reports. $30 \mathrm{~s}$.

Bokusheva, R., Breustedt, G. \& Heidelbach, O. 2006. Measurement and comparison of risk reduction by means of farm yield, area yield, and weather index crop insurance schemes - The case of Kazakhstani wheat farms. International Association of Agricultural Economists Conference, Gold Coast, Australia, August 12-18, 2006

EC. 2013. COUNCIL OF THE EUROPEAN UNION. Brussels, 26 September 2013 (OR. en) Interinstitutional File: 2011/0282 (COD) 13349/1/13 REV 1 AGRI 540 AGRISTR 94 CODEC 1952.

Kragt, M. 2013. The Effect of Changing Cost Vector on Choices and Scale Heterogeneity.

Environmental Resource Econ. 54: 201-221.

Luisetti, T., Bateman, I. \& Turner, K. 2011. Testing the Fundamental Assumption of Choice Experiments: Are Values Absolute or Relative? Land Economics 87: 284-296.

McFadden, D. 2001. Economic Choices. The American Economic Review 91: 351-378.

Morkback, M.R., Christensen, T. \& Gyrd-Hansen, D. 2010. Choke price bias in Choice Experiment. Environmental Resource Econ. 45:537-551.

Myyrä, S., \& Jauhiainen, L. 2013. Farm-level crop yield distribution estimated from country-level crop damage. Food Economics 9: 157-165.

Myyrä, S., Pietola, K. 2012. Indeksipohjaiset sopimukset maatilojen sato- ja tuloriskien hallinnassa (RIMAC). MTT Raportti 63: 35 s.

Smith, V. \& Goodwin, B. 1996. Crop Insurance, Moral Hazard and Agricultural Chemical Use. American Jourmal of Agricultural Economics 78: 428-438. 